\title{
Cataract Surgery Cancellations: An Analysis of Financial and Resident Training Implications at a Major Eye Institution
}

\author{
Sneha Padidam, MD ${ }^{1}$ Douglas Wisner, MD ${ }^{2}$ Brianna Kenney, $\mathrm{BA}^{3}$ Jared Peterson, MD ${ }^{2}$
} Laura Pizzi, PhD, MPH ${ }^{4}$ Benjamin E. Leiby, $\mathrm{PhD}^{5}$ Lisa Hark, PhD, $\mathrm{RD}^{6}$ Robert Bailey, $\mathrm{MD}^{2}$ the Wills Cataract Research Group ${ }^{3}$

${ }^{1}$ Kresge Eye Institute, Detroit, Michigan

${ }^{2}$ Cataract and Primary Eye Care Service, Wills Eye Hospital, Philadelphia, Pennsylvania

${ }^{3}$ Department of Research, Wills Eye Hospital, Philadelphia, Pennsylvania

${ }^{4}$ College of Pharmacy, Thomas Jefferson University, Philadelphia, Pennsylvania

${ }^{5}$ Department of Pharmacology and Experimental Therapeutics, Thomas Jefferson University, Philadelphia, Pennsylvania

${ }^{6}$ Department of Ophthalmology, Columbia University Medical

Center, New York, New York
Address for correspondence Douglas Wisner, MD, Cataract and Primary Eye Care Service, Wills Eye Hospital, Suite 1230, 840 Walnut Street, Philadelphia, PA 19107 (e-mail: dwisner@tbw-eye.com).

Journal of Academic Ophthalmology 2018;10:e1-e4.

\begin{abstract}
Keywords

- cataract surgery cancellation

- cataract surgery

- resident training

- reimbursement information

- preadmission testing

- cancellation rate

- surgical opportunities

Purpose The objective of this study was to assess reasons for cancellation of residentperformed cataract surgery, identify modifiable barriers to completion of the surgery on the scheduled date, and analyze the healthcare reimbursements and educational experiences lost as a result of cancellations.

Setting General eye clinic staffed by residents in a major urban center.

Design Retrospective, observational study.

Methods The study compared patients (older than 18 years) who canceled their cataract surgery to patients who underwent surgery on their scheduled date. Cancellation and reimbursement information was obtained from the surgical coordinator's scheduling book and billing information. Demographic information was obtained from patient electronic medical records, and scheduling logs. A brief phone survey was implemented to identify patient's barriers to surgery if a reason for cancellation was undocumented.

Results The overall cancellation rate over 1 -year was $29.54 \%$ and most common overall reason for cancellation was that preadmission testing (PAT) was not completed in time for the procedure. Overall, $72 \%$ of the cancellations were made within 7 days of the surgery. The total estimated lost potential reimbursement due to cancellation was $\$ 844,370$. The relative loss of surgical opportunities for residents throughout this 1 year period was 230 cases or 29 surgeries per resident.

Conclusion These findings have prompted a new study testing whether on-site mandatory PATs conducted on the same day as the patient's ophthalmology evaluation will reduce cataract surgery cancellation rates.
\end{abstract}

received

January 14, 2016 accepted after revision November 30, 2017
DOI https://doi.org/

10.1055/s-0037-1620236. ISSN 2475-4757.
Copyright $\odot 2018$ by Thieme Medical Publishers, Inc., 333 Seventh Avenue, New York, NY 10001, USA. Tel: +1(212) 584-4662.
License terms

(c) (1) $\ominus$ (\$) 
Cataracts are the leading cause of avoidable blindness in the world and are responsible for approximately $50 \%$ of cases of bilateral vision worse than 20/40 among Caucasian, African American, and Hispanic individuals. ${ }^{1,2}$ Fortunately, surgery to remove cataracts is very safe $^{3}$ and improves both vision and quality of life, translating to significant improvements in real-life activities and emotional and social functioning. ${ }^{4-7}$ Additionally, costs associated with cataract surgical procedures have decreased by $34.4 \%$ from 2000 to $2012 .^{8}$

Given the advantages of cataract surgery, coupled with an increasing population health need, it is vital for ophthalmology residents to obtain high-quality cataract extraction (CE) experience during their training. However, substantial exposure may be precluded by high rates of surgical cancellation.

This study assessed reasons for cancellation of residentperformed cataract surgery, identified modifiable barriers, and analyzed the educational loss to the residents and the monetary loss to the institution as a result of these cancellations.

\section{Methods}

This retrospective, observational study investigated cataract surgery cancellation rates from July 1, 2011, through June 30 , 2012, in the Cataract and Primary Eye Care Clinic at Wills Eye Hospital (WEH). The study compared patients (older than 18 years) who canceled their surgeries to patients who underwent surgery on their originally scheduled date. This information was obtained from the surgical coordinator's scheduling book and cross-referenced with billing information. Patient electronic medical records and scheduling logs were reviewed to identify patient demographics, insurance status, need for advanced surgical clearance, scheduled surgical information, and history of previous cataract surgery. A brief phone survey was implemented to identify patient's barriers to surgery if a reason for cancellation was undocumented. Up to three phone calls were made to each patient. Consent to participate in the survey was obtained over the phone and patients were compensated for their time on the phone with a $\$ 10$ gift card.

\section{Cost Analysis}

Types of lost reimbursements calculated included lost payments in professional fees to the attending surgeons, to the institution, and to the anesthesiologist. Lost payments in professional fees to the attending surgeon were calculated using patient-level data using the specific primary insurance payer. However, for the facility and anesthesiology lost payments, patient-level data were not available. Therefore, Medicare reimbursement was generated by the practice administrators, and applied to all patients where a Medicare plan was the primary insurer. The mean Medicare facility reimbursement per cataract procedure (\$US 2013) was $\$ 1,585$ and $\$ 209$ for anesthesiology (inclusive of a base rate for anesthesia services plus anesthesia time units, per procedure). If a Medicaid plan was listed as the primary insurance payer, it was assumed that facility and anesthesiology reimbursements were 20\% lower than Medicare
(\$1,427 and $\$ 188$, respectively). However, if a private plan was listed as the primary insurance payer, reimbursements were assumed to be $20 \%$ higher ( $\$ 1,902$ for the facility and $\$ 251$ for anesthesia). In the absence of a primary insurance payer, we conservatively assumed that reimbursements lost would have been $\$ 0$. This included 12 individuals who were documented as having charity care or no insurer listed.

\section{Statistical Analysis}

All statistical analyses were conducted using SAS version 9.3 (SAS Institute, Cary, NC). Descriptive statistics were presented as means and standard deviations for continuous variables, and frequencies and percentages for categorical variables. Chi-square and 2 -sample $t$-tests were conducted to identify associations between risk factors and the primary outcome variable of surgery cancellation. Risk factors analyzed included age, gender, race, previous cataract surgery, distance from WEH, visual acuity, season, and primary insurance type. All statistical analyses were two-sided, and $p$-values less than 0.05 were considered statistically significant.

\section{Results}

Between July 1, 2011, and June 30, 2012, out of 1,083 of cataract surgeries, 319 (29.45\%) were canceled. In the cancellation group, $65.54 \%$ (165/251) of patients who canceled cataract surgery went on to complete surgery at a later time. African Americans, patients who previously had cataract surgeries, and patients who lived within 10 miles of WEH, were statistically more likely to cancel surgery $(p=0.039$, $p=0.004$, and $p=0.008$, respectively; - Table $\mathbf{1}$ ).

After assessing reasons for cancellation of the 319 cases, we identified reasons for cataract surgery cancellation in a total of 251 cases ( $\mathbf{-}$ Table 2 ). The majority of these surgical cases $(35.6 \%, 89 / 251)$ were canceled because preadmission testing (PAT) was not completed in time, which includes an electrocardiography, physical exam, blood pressure reading, and blood glucose test in patients with diabetes (-Table 2 ). Additionally, 47\% (118/251) of cancellations were made on the day before or the day of the surgery, while $25 \%(63 / 251)$ of cancellations occurred 3 to 7 days prior to surgery.

The total estimated lost reimbursement due to canceled cataract surgery cases was $\$ 844,370$. Cancellations made within 7 days of the cataract surgery (72\%) accounted for $\$ 497,720$ (59\%) of the estimated loss.

The total loss of 230 cataract surgical cases for residents occurred throughout this year. Divided among eight residents performing cataract surgeries, this represented a loss of 29 cataract surgery opportunities per resident over the year.

\section{Discussion}

Previous studies have not quantified cancellation rates of resident-performed cataract surgeries and attributable lost reimbursements. A study focusing on ophthalmic surgeries cancelled at an ambulatory surgical center found a 5.3\% cancellation rate within 24 hours of the procedure. ${ }^{9}$ Argo 
Table 1 Characteristics of patients whose cataract extractions were canceled versus controls $(n=586)$

\begin{tabular}{|c|c|c|c|}
\hline Variable & $\begin{array}{l}\text { Cancellation } \\
n=251\end{array}$ & $\begin{array}{l}\text { Control } \\
n=335\end{array}$ & p-Value \\
\hline Age, mean \pm SD & 66.7 (11.9) & $67.1(12.2)$ & 0.7 \\
\hline \multicolumn{4}{|l|}{ Gender, $n(\%)$} \\
\hline Male & $94(37.45 \%)$ & $136(40.6 \%)$ & \multirow[t]{2}{*}{0.44} \\
\hline Female & $157(62.55 \%)$ & 199 (59.4\%) & \\
\hline \multicolumn{4}{|l|}{ Ethnicity, $n(\%)$} \\
\hline African American & $167(66.8 \%)$ & 185 (56.75\%) & \multirow[t]{4}{*}{0.039} \\
\hline Caucasian & $57(22.8 \%)$ & $112(34.46 \%)$ & \\
\hline Hispanic & $11(4.4 \%)$ & $14(4.29 \%)$ & \\
\hline Asian & $12(4.8 \%)$ & $13(3.99 \%)$ & \\
\hline \multicolumn{4}{|c|}{ Previous cataract extraction, $n(\%)$} \\
\hline No & $193(80.42 \%)$ & 294 (89.09\%) & \multirow[t]{2}{*}{0.004} \\
\hline Yes & $47(19.58 \%)$ & $36(10.91 \%)$ & \\
\hline \multicolumn{4}{|l|}{ Distance, $n$ (\%) } \\
\hline$<1$ mile & $7(2.79 \%)$ & $5(1.49 \%)$ & \multirow[t]{5}{*}{0.008} \\
\hline $1-4$ miles & $92(36.65 \%)$ & $109(32.54 \%)$ & \\
\hline 5-10 miles & $86(34.36 \%)$ & $87(25.97 \%)$ & \\
\hline 10-20 miles & $46(18.33 \%)$ & $86(25.67 \%)$ & \\
\hline$>20$ miles & $20(7.97 \%)$ & $48(14.33 \%)$ & \\
\hline
\end{tabular}

et al reported a $9 \%$ cancellation rate for ophthalmic surgeries and also showed that surgeons at low cancellation rate sites gave patients written preoperative instruction and had a higher use of preoperative clinic visits. ${ }^{10}$

In our study, cancellation rates for resident-performed cataract surgery were higher at $29.54 \%$, with incomplete PAT being the most common reason $(35.6 \%)$ for cancellation (-Table 2). This high rate of cancellation impacts residents who are losing valuable surgical training experience. Previous studies reported that complication rates following cataract surgery drastically decrease as the surgeon's experience (surgical volume) increases. ${ }^{11-13}$ Our study found that 230 cases (29 cases per ophthalmology resident) were lost throughout the 12-month period, representing a significant loss in surgical training opportunities.

Table 2 Reasons for cancellation $(n=319)$

\begin{tabular}{|l|l|}
\hline Reasons for cancellation & $\boldsymbol{n}(\%)$ \\
\hline $\begin{array}{l}\text { Preadmission testing not } \\
\text { completed in time }\end{array}$ & $89(35.6 \%)$ \\
\hline Patient rescheduled surgery & $52(20.7 \%)$ \\
\hline Systematic health issues & $41(16.4 \%)$ \\
\hline Unattained specialist referrals & $23(9.1 \%)$ \\
\hline Anesthesiologist cancelled & $22(8.7 \%)$ \\
\hline Other & $24(9.5 \%)$ \\
\hline $\begin{array}{l}\text { Unable to determine } \\
\text { reason (missing) }\end{array}$ & 68 \\
\hline
\end{tabular}

High rates of surgical cataract cancellations also affect the institution. Seventy-two percent of cancellations occurred within 7 days of the procedure, which does not leave enough time to ensure the operating room slot is filled by another patient and results in loss of revenue by the institution. The estimated lost reimbursements due to cancellation totaled $\$ 844,370$, of which $\$ 391,884$ were facility fees. While the dollar value of lost reimbursements is significant, this figure underestimates the true financial impact of cataract cancellations, since losses due to underused fixed resources (i.e., staff, surgical equipment, room) were beyond the scope of the analysis.

Our findings can serve to inform interventions to reduce cataract surgery cancellations. Some potential interventions include same-site PATs, contacting and scheduling patients with their own primary care physician (PCP), providing patients with a list of local PCPs if they are not under the care of a PCP, and reaching out to each patient via a systematic phone call 10 days prior to surgery.

Various limitations of this study exist. This was a retrospective study reliant on the institution's existing systems for gathering data, and data for some cancellations were unknown. Additionally, the estimated facility and anesthesia reimbursements lost were calculated via blended payer rates as opposed to patient-level data. Lastly, this study fails to consider the morbidity burdens experienced by patients due to uncorrected cataracts.

The findings from this study have prompted our institution to develop and initiate a randomized, controlled, clinical trial evaluating on-site required PATs to reduce resident- 
performed cataract surgery cancellations and improve the quality of care for patients.

\section{Authors' Contributions}

Sneha Padidam: Acquisition, analysis, and interpretation of data; drafting of the manuscript; and administrative, technical, or material support.

Douglas Wisner: Conception and design of the study; acquisition, analysis, and interpretation of data; drafting of the manuscript; statistical analysis; critical revision of the manuscript; obtaining funding; administrative, technical, and material support; and supervision of the study. Brianna Kenney: Conception and design of the study, drafting of the manuscript, obtaining funding, and supervision of the study.

Jared Peterson: Conception and design of the study; acquisition, analysis, and interpretation of data; critical revision of the manuscript; obtaining funding; administrative, technical, and material support; and supervision of the study. Laura Pizzi: Conception and design of the study; acquisition, analysis, and interpretation of data; statistical analysis; drafting and critical revision of the manuscript; and administrative, technical, or material support.

Benjamin E. Leiby: Analysis and interpretation of data, critical revision of the manuscript, and statistical analysis. Robert Bailey: Conception and design of the study; acquisition, analysis, and interpretation of data; critical revision of the manuscript; obtaining funding; administrative, technical, and material support; and supervision of the study. Wills Cataract Research Group: Conception and design of the study; acquisition, analysis, and interpretation of data; statistical analysis; drafting and critical revision of the manuscript; administrative, technical, or material support; obtaining funding; administrative, technical, and material support; and supervision of the study.

Conflicts of Interest

Douglas Wisner: Resident Innovation grant during the conduct of the study and personal fees from Wills Eye Hospital, outside the submitted work.

Jared Peterson: Wills Eye Innovation Research Grant during the conduct of the study.

Laura Pizzi: Wills Eye Innovation Research Grant during the conduct of the study.

All other authors have no conflicts of interest to disclose.

\section{Funding Source}

Wills Eye Innovation Research Grant (grant number: INV \#12-025). The funder had no role in the following: design and conduct of the study; collection, management, analysis, and interpretation of the data; and preparation, review, or approval of the manuscript.

\section{References}

1 Pascolini D, Mariotti SP. Global estimates of visual impairment: 2010. Br J Ophthalmol 2012;96(05):614-618

2 Congdon N, O'Colmain B, Klaver CC, et al; Eye Diseases Prevalence Research Group. Causes and prevalence of visual impairment among adults in the United States. Arch Ophthalmol 2004;122 (04):477-485

3 Clark A, Morlet N, Ng JQ Preen DB, Semmens JB. Whole population trends in complications of cataract surgery over 22 years in Western Australia. Ophthalmology 2011;118(06): 1055-1061

4 Busbee BG, Brown MM, Brown GC, Sharma S. Incremental costeffectiveness of initial cataract surgery. Ophthalmology 2002;109 (03):606-612, discussion 612-613

5 Tseng VL, Yu F, Lum F, Coleman AL. Risk of fractures following cataract surgery in Medicare beneficiaries. JAMA 2012;308(05): 493-501

6 Ayaki M, Muramatsu M, Negishi K, Tsubota K. Improvements in sleep quality and gait speed after cataract surgery. Rejuvenation Res 2013;16(01):35-42

7 Lamoureux EL, Fenwick E, Pesudovs K, Tan D. The impact of cataract surgery on quality of life. Curr Opin Ophthalmol 2011; 22(01):19-27

8 Brown GC, Brown MM, Menezes A, Busbee BG, Lieske HB, Lieske PA. Cataract surgery cost utility revisited in 2012: a new economic paradigm. Ophthalmology 2013;120(12):2367-2376

9 Henderson BA, Naveiras M, Butler N, Hertzmark E, FerrufinoPonce Z. Incidence and causes of ocular surgery cancellations in an ambulatory surgical center. J Cataract Refract Surg 2006;32 (01):95-102

10 Argo JL, Vick CC, Graham LA, Itani KM, Bishop MJ, Hawn MT. Elective surgical case cancellation in the Veterans Health Administration system: identifying areas for improvement. Am J Surg 2009;198(05):600-606

11 Ament CS, Henderson BA. Optimizing resident education in cataract surgery. Curr Opin Ophthalmol 2011;22(01):64-67

12 Martin KR, Burton RL. The phacoemulsification learning curve: per-operative complications in the first 3000 cases of an experienced surgeon. Eye (Lond) 2000;14(Pt 2):190-195

$13 \mathrm{Ng}$ DT, Rowe NA, Francis IC, et al. Intraoperative complications of 1000 phacoemulsification procedures: a prospective study. J Cataract Refract Surg 1998;24(10):1390-1395 